\title{
GREEN SYNTHESIS AND FUNCTIONAL EVALUATION OF SILVER NANOPARTICLES FROM WHITE MELON SOURCE
}

\author{
Dhanashri Kathole*, Itishree Vaidya and Pooja Maurya
}

\begin{abstract}
Silver nanoparticles (AgNPs) with optimum surface charge, shape, size and colloidal stability were synthesized by using white melon fruit extract as bioreductant. AgNPs formed has particle sizes ranging between 30-50 $\mathrm{nm}$ with endcapping resulting into good stability. This green method is really found to be the simple, easy, cost effective and ecofriendly for the synthesis of AgNPs. The article also describes functional evaluation of AgNPs for antibacterial, antioxidant, antidiabetic and anticancer activities. Promising anticancer activity was shown for Hep-G2 and MCF-7 Breast Cancer cell lines at 7 and $15 \mathrm{mM}$ concentration with Adriamycin as a standard.
\end{abstract}

Keywords: Silver nanoparticle, Green synthesis, Antioxidant and Catalytic agent

\section{INTRODUCTION}

Metal nanoparticles are manufactured worldwide owing to their wide range of applications in the, constructions, electronics, textiles, catalysis and water treatment, agriculture and foods and medicinal field having anti-cancer, anti-diabetic, antibacterial activities ${ }^{1 .}$ Amongst several noble metal nanoparticles, silver nanoparticles have attained a special focus due to its unique physical, chemical and biological properties ${ }^{2}$. Herbs and herbal derivatives are of great research interest due to their applications in therapeutics. Green protocol of synthesizing metal nanoparticles has emerged as an alternative to overcome the limitation of conventional methods. Green synthesis spotlights on processes that minimize the use and generation of hazardous substances. It is better to prevent waste than to treat or clean up waste after it is formed ${ }^{3}$. Chemical synthesis methods (e.g., chemical reduction, sol gel technique, etc.) involve the usage of toxic chemicals, formation of hazardous byproducts, and contamination from precursor chemicals ${ }^{4}$. Hence, there is a growing need to develop clean, nontoxic, and environment-friendly procedures for nanoparticle synthesis. Thus to solve the objective biological approaches derived from plant sources in the form of extracts exhibits superiority over chemical or biological methods. The nanoparticles synthesis with plant based biological molecules makes it suitable ${ }^{5 ; 6}$. Several physical and chemical methods have been used for synthesizing and stabilizing silver nanoparticles ${ }^{7}$. In the present research work we have emphasized on the green synthesis of silver nanoparticles using fruit extract of Benincasa hispida (Family: Cucurbitaceae). We have evaluated them for antibacterial, antidiabetic, antioxidant, anticancer, and catalytic activities.

\section{MATERIAL AND METHODS}

Silver nitrate, $\mathrm{AgNO}_{3}, 99.0 \%$ was purchased from Molychem, Mumbai. Unripe fruits of White melon were procured from the local market \& used to prepare an extract. Alpha amylase was obtained as a gift sample from Enzyme bioscience Pvt. Ltd, Gujrat

\section{Preparation of White melon extract}

The White melon fruit rind was removed, grated and about $50-80 \mathrm{gm}$ of fruit gratings were boiled in $500 \mathrm{ml}$ distilled water for $30 \mathrm{~min}$. Extract was filtered and stored in refrigerator at $8^{\circ} \mathrm{C}$.

\section{Preparation of silver nanoparticles}

$10 \mathrm{ml}$ of white melon fruit extract mixed with $50 \mathrm{ml}$ of $3 \mathrm{mM}$ aqueous solution of silver nitrate was stirred at $25^{\circ} \mathrm{C}$ for one $\mathrm{hr}$, followed by centrifuging solution at $12,000 \mathrm{rpm}$ for $30 \mathrm{~min}$. The solid residue 
layer containing silver nanoparticles was dispersed in methanol. The pure residue was dried perfectly in an oven overnight at $50^{\circ} \mathrm{C}$.

\section{Functional Evaluation of Silver Nanoparticles}

Functional evaluation of synthesized AgNPs is important to understand its effectiveness and new avenues for applications.

\section{i. Silver nanoparticles as antibacterial agents}

The antibacterial assays were done on human pathogens such as Staphylococcus aureus and Escherichia coli by cup plate method by using standard protocol. ${ }^{8}$

\section{ii. Silver nanoparticles as antidiabetic agents Inhibition of $\alpha$-amylase enzyme assay}

In series of test tubes namely $0,200,400,600,800,1000 \mu$ of silver nanoparticles solution was taken and added $500 \mu \mathrm{l}$ of $\alpha$-amylase $(0.5 \mathrm{mg} / \mathrm{ml})$ solution made in $0.0002 \mathrm{M}$ phosphate buffer $(\mathrm{pH}$ 6.9) and all test tubes were incubated at $25{ }^{\circ} \mathrm{C}$ for $10 \mathrm{~min}$. followed by addition of $500 \mu \mathrm{l}$ of a $1 \%$ starch solution made in $0.02 \mathrm{M}$ sodium phosphate buffer $(\mathrm{pH}$ 6.9). All test tubes were then incubated at $25^{\circ} \mathrm{C}$ for $10 \mathrm{~min}$. to each test tube added $1 \mathrm{ml}$ of 3,5 dinitrosalicylic (DNS) acid color reagent. The test tubes were then incubated in a boiling water bath for $5 \mathrm{~min}$, cooled to room temperature, diluted suitably with distilled water and absorbance was measured at $540 \mathrm{~nm}$ against blank with voglibose $(5 \mathrm{mg} / \mathrm{ml})$ as standard.

\section{iii. Silver nanoparticles as antioxidant (free radical scavenging) agents}

To a set of test tubes containing $3 \mathrm{ml}$ methanol, $100 \mu \mathrm{l}$ of 2,2-diphenyl-1-picrylhydrazyl (DPPH) reagent $(0.1 \mathrm{mg} / \mathrm{ml})$ was added .and initial absorbance was measured at $516 \mathrm{~nm}$. Against blank with

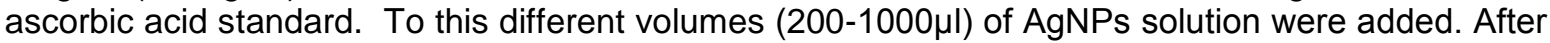
$4 \mathrm{~min}$. the percentage reduction of absorbance of each solution was recorded. A blank solution

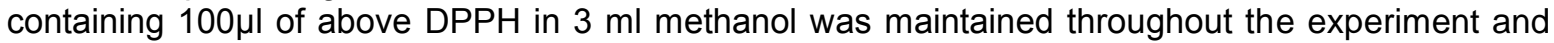
absorbance recorded every 30 minutes up to $3 \mathrm{hr}$. there was no change in the absorbance showing the stability of free radical.

\section{iv. Silver nanoparticles as anticancer agents}

To study anticancer activity of silver nanoparticles, white melon fruit extract and $3 \mathrm{mM}$ aqueous solution of silver nitrate solution was added into $1: 5$ ratio. The reaction was continued at $25^{\circ} \mathrm{C}$.

AgNPs were tested on four different concentrations namely 1,3,5,10 mM using Adriamycin as a standard drug for two cell lines namely Hep-G2 (Human) and MCF-7 Breast Cancer (Human) Species cell lines using Sulforhodamine B Assay.

\section{v. Silver nanoparticles as catalytic agent towards nitrophenol reduction}

The catalytic activity of silver nanoparticles were tested by reducing 4- nitro phenol to 4- amino phenol in presence of sodium borohydride and AgNPs. Both solutions namely $0.25 \mathrm{M} \mathrm{NaBH}_{4}$ and 4-nitrophenol one $\mathrm{ml}$ each were placed in a conical flask followed by addition of $2-3 \mathrm{ml} 3 \mathrm{mM}$ green synthesized AgNPs and the reaction mixture was allowed to stand for $30 \mathrm{~min}$. Reaction was spectrophotometrically monitored in the wavelength range of $200-700 \mathrm{~nm}$.

\section{vi. Silver nanoparticles as degradation of organic dyes}

The catalytic activity of green synthesized AgNPs was demonstrated by degrading hazardous dyes. One to two $\mathrm{ml}$ of green synthesized AgNPs was added to three separate test tubes containing $10 \mathrm{ml}$ of Methylene blue, Methyl orange and Methyl red dye solution and mixed ultrasonically for 15 min. Thereafter $3 \mathrm{ml}$ of each mixed solution was used to evaluate the catalytic degradation of dyes. The progress of reactions was monitored using UV-visible spectrophotometer by measuring absorbance maxima of dyes after $24 \mathrm{hrs}$. of incubation against control set maintained without AgNPs for each dye and measured for absorbance.

\section{RESULTS AND DISCUSSION}

Silver is placed at lower rank in electrochemical series and in synthesis of nanoparticles we are allowing silver ions to get combined with an electron to give $\mathrm{Ag}$ nanoparticle. Standard reduction potential for $\mathrm{Ag}^{+}$ion is $+0.799 \mathrm{~V}$. It suggests $\mathrm{Ag}+$ can easily get converted to $\mathrm{Ag}$ nanoparticle in presence of mild bioreductant ${ }^{9}$. 


$$
\mathrm{Ag}^{+}+\mathrm{e}-\stackrel{\text { Reduction }}{\stackrel{\stackrel{\text { Oxidation }}{\leftarrow}}{\leftarrow}} \quad \mathrm{Ag}^{0}
$$

We have selected bioreductant source as fruit extract of white melon for synthesizing silver nanoparticles. The method developed is ecofriendly, cost effective, easily scalable and requiring lesser time of synthesis. Silver nanoparticles showed fairly well-defined dimensions. The synthesized AgNPs was confirmed by visual observation and various analytical techniques.

\subsection{Characterisation of synthesized silver nanoparticles UV VIS. Spectroscopy Analysis}

The reduction of pure $\mathrm{Ag}+$ ions was monitored by measuring the UV-Vis spectrum of the reaction medium after diluting a small aliquot of sample into distilled water. It is well known that silver nanoparticles exhibit reddish brown color in aqueous solution due to excitation of surface Plasmon vibrations in silver nanoparticles. The absorption spectra of silver nanoparticles formed in the reaction media has shown maximum absorbance at $445 \mathrm{~nm}$ (Fig 1) with broadening of peak indicated that the formation of AgNPs which are poly-dispersed.

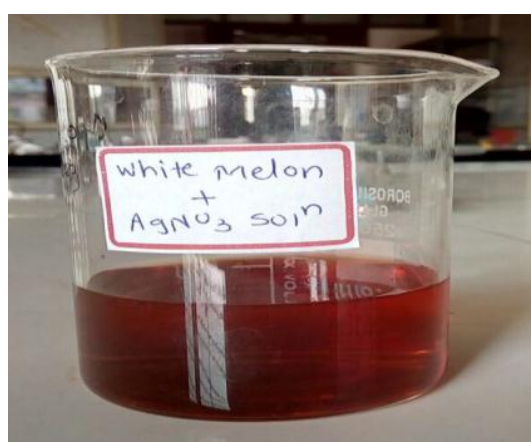

Fig. 1: a) AgNPs

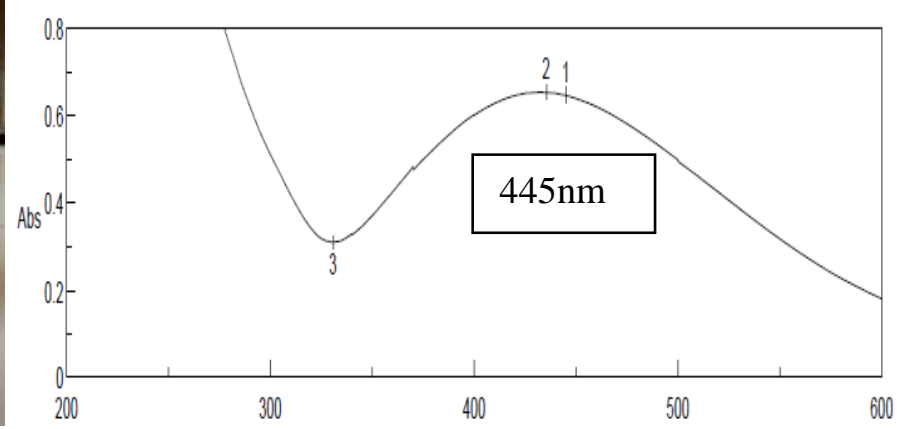

b) UV-VIS spectra of AgNPs using white melon

\section{FT-IR Analysis}

Figure 2 showed FT-IR spectrum of synthesized AgNPs. The broad band appearing at $3327.35 \mathrm{~cm}^{-1}$ is assigned for $\mathrm{O}-\mathrm{H}$ stretching vibration for triterpenoid lupeol in extract indicating the presence of hydroxyl groups in the reducing agent. The intense peaks at 1383.98 and $1649.21 \mathrm{~cm}^{-1}$ corresponds to $\mathrm{C}-\mathrm{H}$ bending as well as to $\mathrm{C}=\mathrm{C}$ stretching for constituent lupeol or 9,12-Octadecadienoic ester of the white melon fruit extract. The medium intensity bands at $1743.82 \mathrm{~cm}^{-1}$ in the spectrum of the AgNPs indicate the presence of carbonyl groups for 9,12-Octadecadienoic ester in the material bound to the AgNPs. Thus the result of this FTIR spectroscopic study confirmed that the white melon fruit extract has the ability to perform dual functions of reduction $\left(\mathrm{Ag}^{+}\right.$to $\left.\mathrm{Ag}^{0}\right)$ and stabilization of silver nanoparticles.

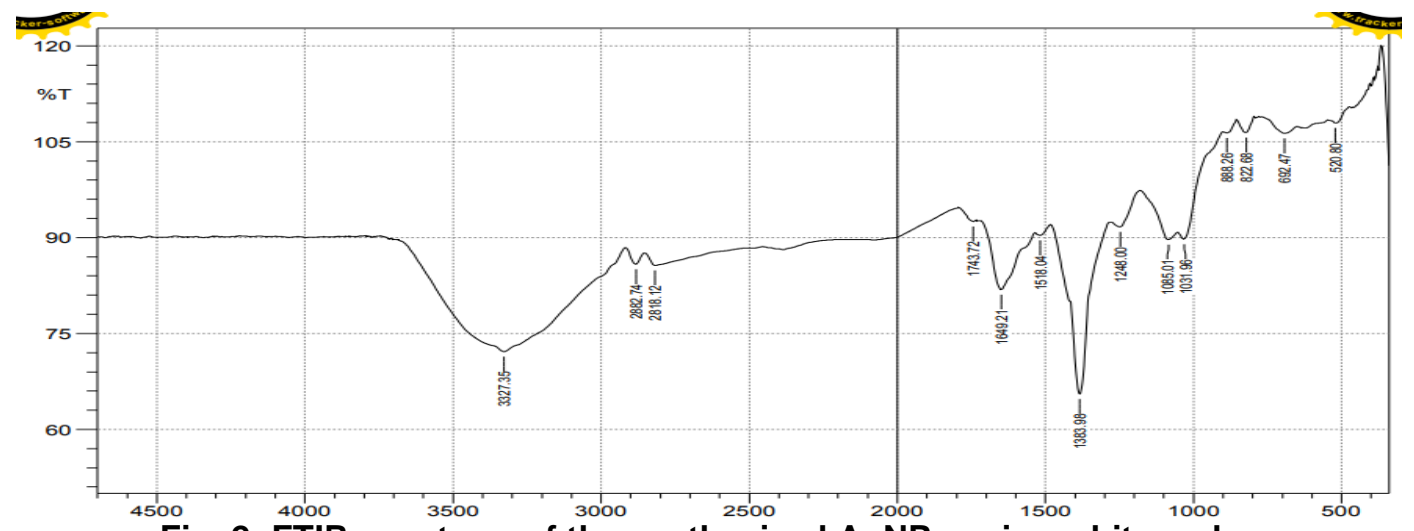

Fig. 2: FTIR spectrum of the synthesized AgNPs using white melon 


\section{Scanning Electron Microscopy}

The morphology and structure of synthesized AgNPs by green method are disclosed in Fig.3.(a),(b),(c) and (d). CRYO SEM with magnification of $15000 \mathrm{X}$ i.e. fig.3(a) revealed the stabilization phenomena for AgNPs. It appears that the silver nanoparticles are encapsulated by end capping agents from white melon extract. The formed networks may ease the excellent stability of the nanoparticles through electrostatic and steric effects which further promote the stabilization of silver nanoparticles. In Fig.3(b) and 3(c) of magnification 45000X and 65000X respectively the distribution of AgNPs in the network of endcapping agent is more clear.

The morphology of white melon fruit extract mediated synthesized AgNPs showed in fig. 3(d) with magnification of $80000 X$. The particle size of nanoparticles have diameter $32 \mathrm{~nm}, 45.2 \mathrm{~nm}$ and 50.3 $\mathrm{nm}$. with smooth surface, slightly spherical in shape and uniformly distributed.

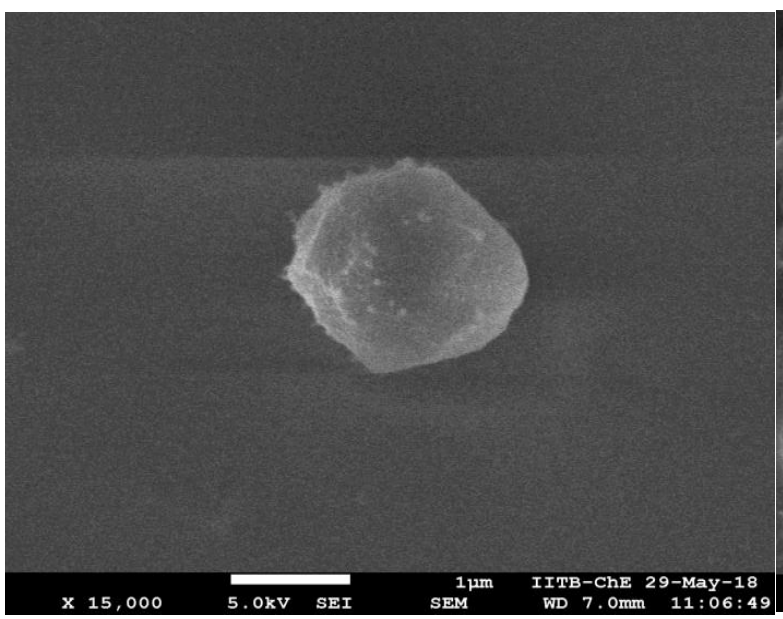

(a)

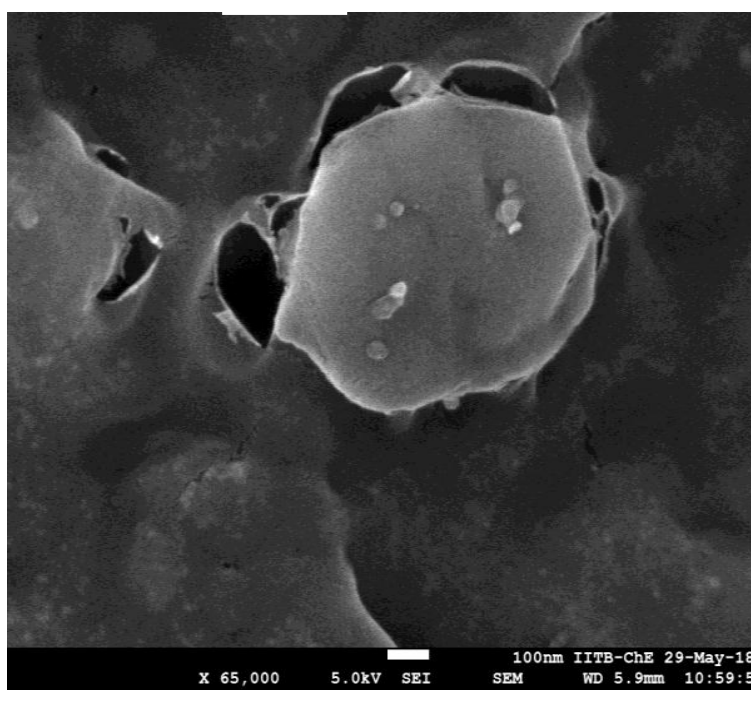

(c)

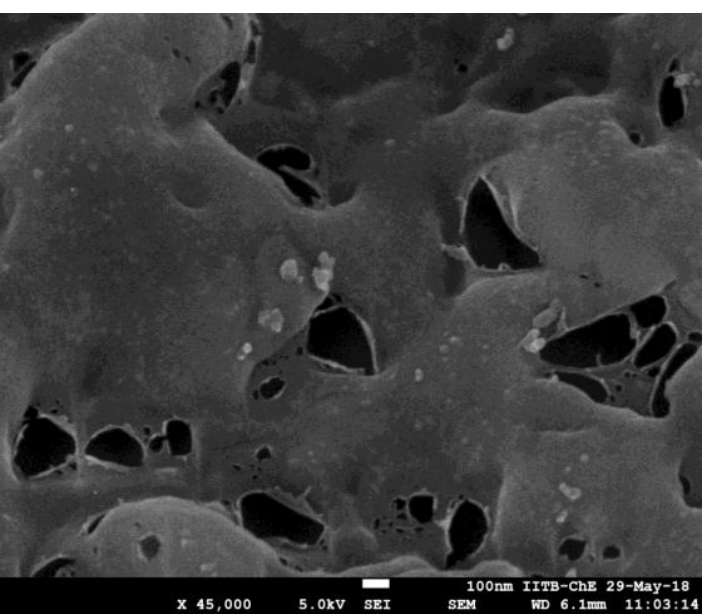

(b)

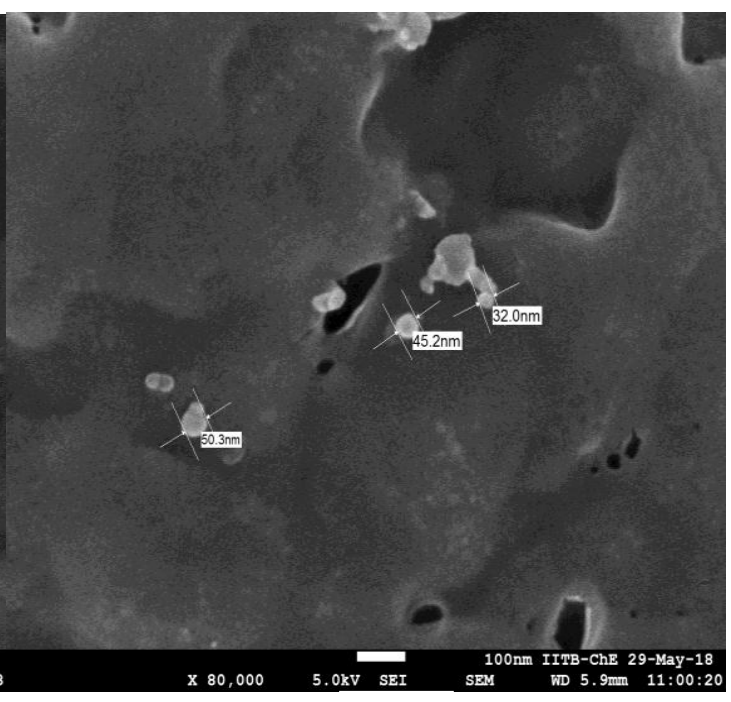

(d)

Fig. 3: CRYO FEG-SEM (a)15000X, (b) 45000X, (c) 65000X and (d) $80000 \mathrm{X}$

\section{Stability Study}

The stability of synthesized nanoparticle was established over a period of six months. Green synthesized silver nanoparticles from white melon fruit extract were stored at $40^{\circ} \mathrm{C} \pm 2^{\circ} \mathrm{C} / 75 \% R H$, $5 \pm 2^{0} \mathrm{C}$ for six months. No aggregation or any significant change in the SPR occurred for AgNPs as shown in fig. 4 

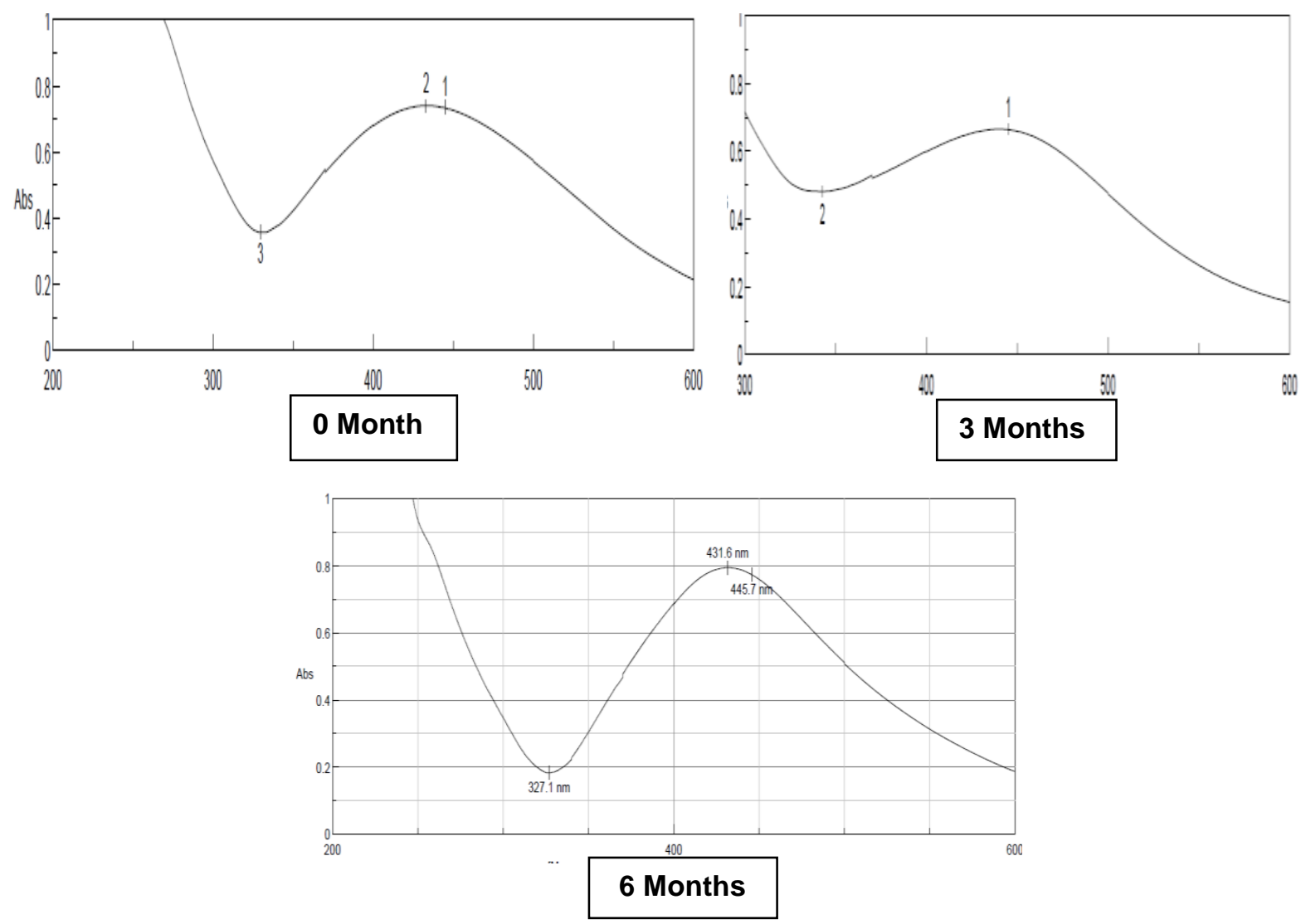

Fig 4: UV-vis spectra of AgNPs

for stability study

\begin{tabular}{|c|c|c|c|}
\hline Sr. No & Position & Intensity & Month \\
\hline 1. & $445 \mathrm{~nm}$ & 0.732536 & 0 \\
\hline 2. & $445 \mathrm{~nm}$ & 0.662305 & 3 \\
\hline 3. & $445.7 \mathrm{~nm}$ & 0.768704 & 6 \\
\hline
\end{tabular}

Thus, the synthesized AgNPs by green route were stable and could, therefore, be useful for various biomedical applications.

\subsection{Functional Evaluation of Silver Nanoparticles}

i. Silver Nanoparticles as Antibacterial Agents

AgNPs showed the higher zone of inhibition for antibacterial activity for E.coli. as $12 \mathrm{~mm} \pm 0.2$ and with standard $\mathrm{AgNO} 3$ showing as $6 \mathrm{~mm} \pm 0.1$, while lower antibacterial activity against S.aureus with zone of inhibition just $9 \mathrm{~mm} \pm 2$ compared to std. $\mathrm{AgNO}_{3}$ showing $11 \mathrm{~mm}$ solution at $50 \mathrm{mM}$ concentration.

\section{ii. Silver nanoparticles as anti-diabetic agents}

A therapeutic approach to decrease the hyperglycemia is to inhibit the carbohydrate digesting enzymes (alpha amylase), thereby preventing the breakdown of carbohydrates into monosaccharides which is a main cause of increasing blood glucose level. Therefore, developing compounds having inhibitory activities towards carbohydrate hydrolyzing enzymes may be a useful way to manage diabetes.

As shown in figure 5 the anti-diabetic activity of AgNPs showed moderate alpha amylase inhibition $(55.31 \%$ at $1000 \mu \mathrm{l} / \mathrm{ml})$ when compared with voglibose as standard $(73 \%$ at $1000 \mu \mathrm{l} / \mathrm{ml})$ in a concentration dependent manner following incubation with various concentrations of AgNPs. With an increasing concentration of AgNPs, the enzymatic activity level was reduced remarkably. (Fig 5) following graph is for enzyme activity against concentration in $\mu \mathrm{l} / \mathrm{ml}$. 


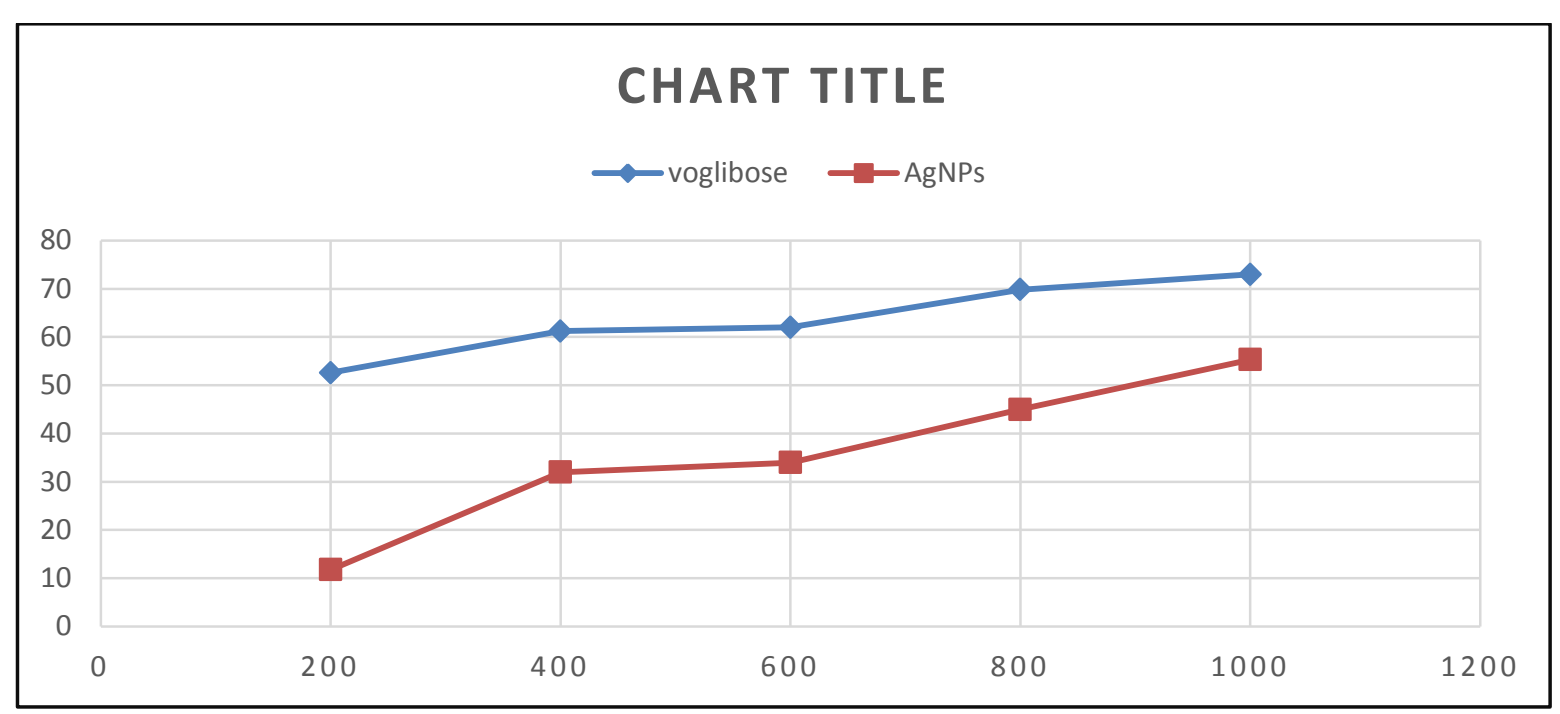

Fig. 5: Antidiabetic activity of synthesized AgNPs based on inhibition of alpha-amylase activity

iii. Silver nanoparticles as antioxidant (free radical scavenging) agents

In vitro antioxidant activity was carried out by DPPH radical scavenging activity method. The standard Ascorbic acid shows a percent scavenging activity of $29.63 \%$ at a concentration of $1000 \mu \mathrm{l} / \mathrm{ml}$ whereas the AgNPs shows a percentage scavenging activity of $23.74 \%$ at a concentration of $1000 \mu \mathrm{l} / \mathrm{ml}$.(Fig.6)

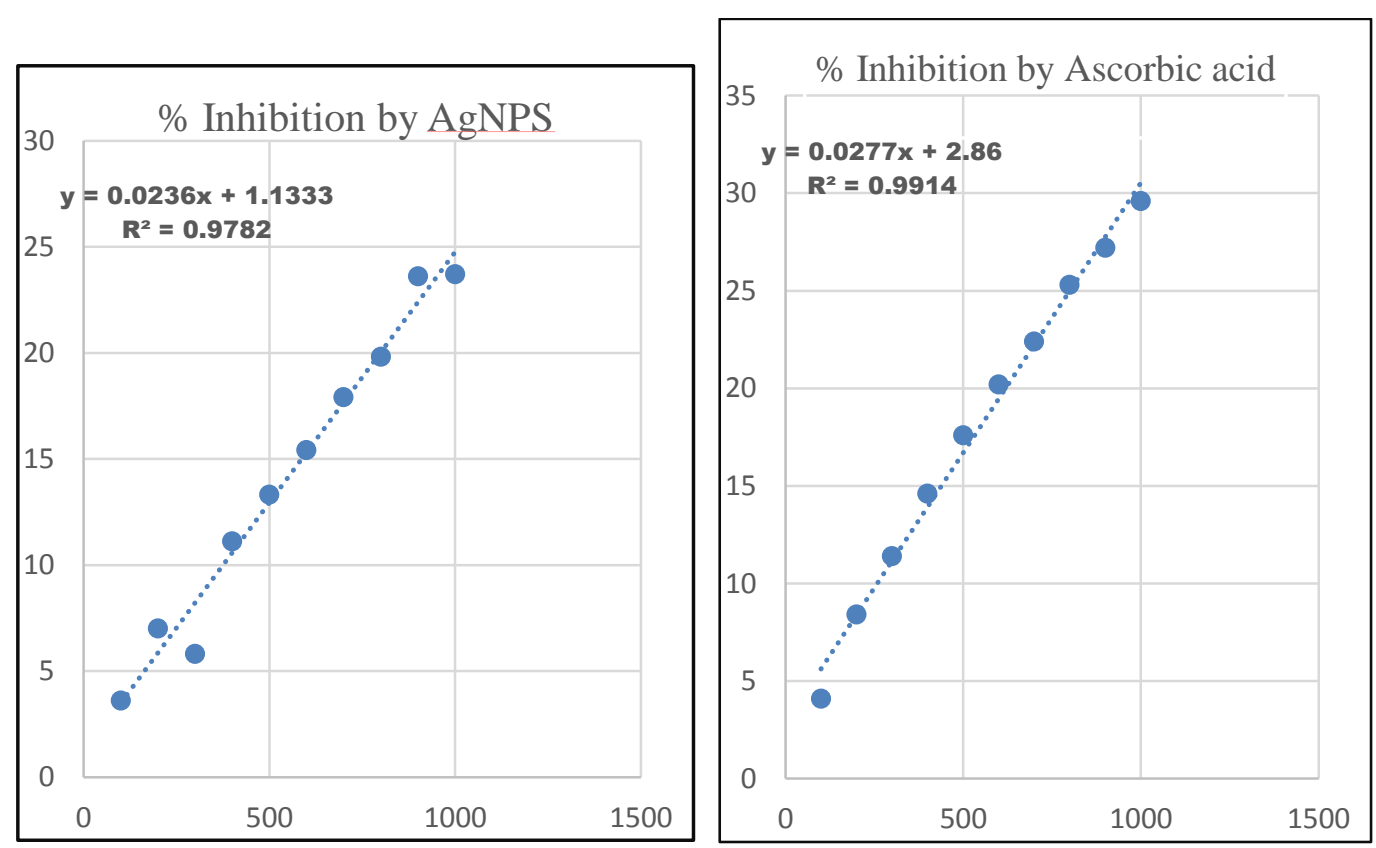

Fig. 6: Antioxidant activity of AgNPs and standard

\section{iv. Silver nanoparticles as anticancer agents}

Generally, green synthesized silver nanoparticles have shown to demonstrate anticancer activity with no or less toxic manner, depending on the agents used for reducing and capping the silver nitrate into silver ${ }^{10}$.

Silver nanoparticle with best antioxidant activity taken up for further anticancer screening on two cell lines namely were Hep-G2 (Human) and MCF-7 Breast Cancer (Human) Species cell lines using Sulforhodamine B Assay. AgNPs were tested on four different concentrations namely 1,3,5,10 mM were coded as NP-1,2,3 and4 respectively and were tested using Adriamycin as a standard drug.

Compounds elicited activity against MCF-7 and Hep-G2 as depicted in Fig.7. It was comparable to the standard drug Adriamycin. Out of four different concentrations NP-3 (at 5mM) and NP-4 (at $10 \mathrm{mM}$ ) showed appreciable anticancer activity against both cell lines. Compound NPs-3 and NPs-4 exhibited GI50 of $<10$ on both cell lines. According to percent control growth MCF-7 cell line shows 
greater anticancer activity than Hep-G2 cell line. It can be suggested that higher anticancer activity can be obtained at higher concentrations of the AgNPs.
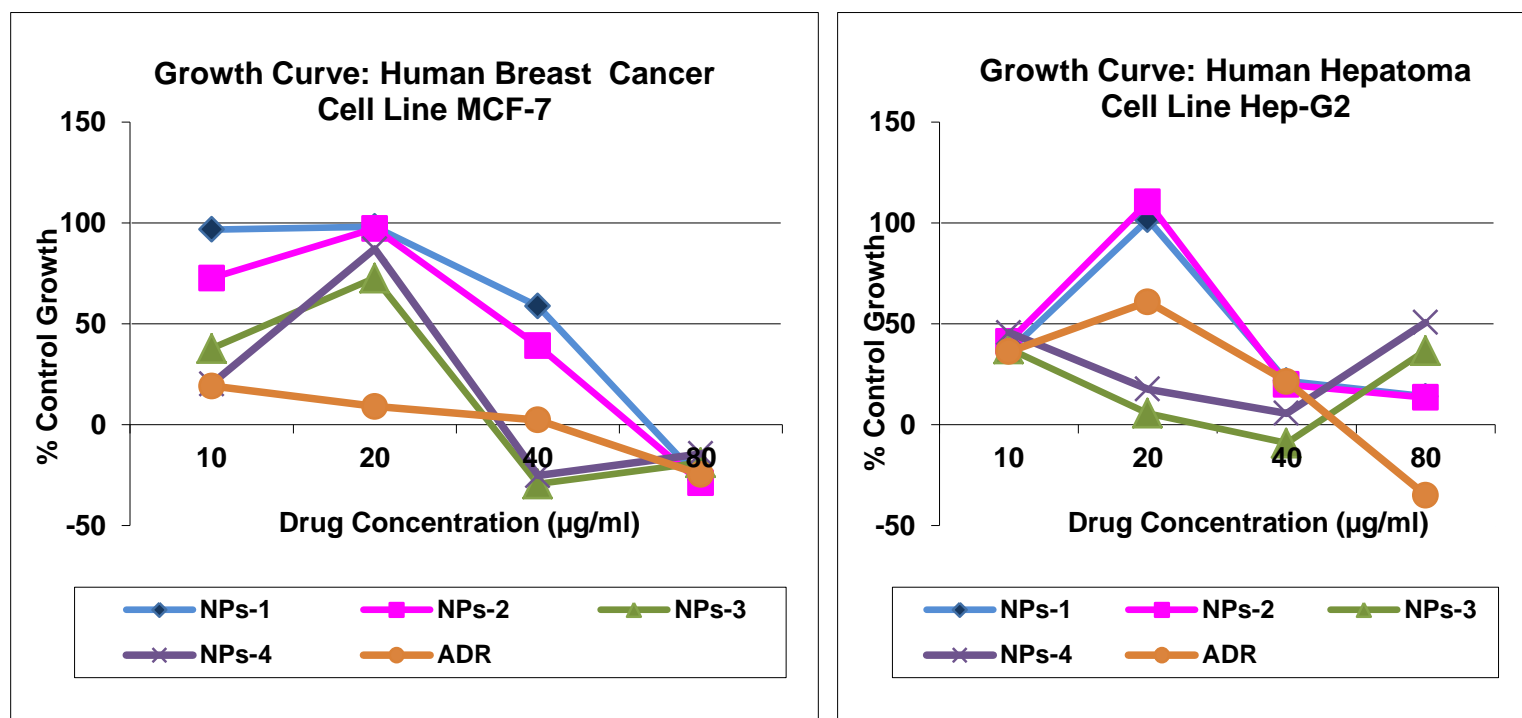

Fig. 7: Growth Curve of MCF-7 and Hep-G2

\section{v. Silver nanoparticles as catalytic agent towards nitrophenol reduction}

The formation of nitro phenolate anion from 4-nitrophenol is a crucial step for the reduction phenomenon and is usually achieved with the aid of sodium borohydride $\left(\mathrm{NaBH}_{4}\right)$. The reducing agent $\mathrm{NaBH}_{4}$ requires the hydrogenation of nitro compounds for the formation of aminophenol and is achieved with the nanoparticles. The reduction of 4-nitrophenol under the influence of nanoparticles has been considered as a model reaction to evaluate the catalytic efficiency of prepared nanomaterials. p-Nitrophenol exhibited an absorption peak at $317 \mathrm{~nm}$ and the addition of $\mathrm{NaBH}_{4}$ shifted the corresponding peak to $400 \mathrm{~nm}$, representing the formation of $p$-nitro phenolate ions after the addition of $\mathrm{NaBH}_{4}$. UV spectra depicts that $\mathrm{p}$-nitrophenol was completely converted into $\mathrm{p}$ aminophenol after addition of AgNPs solution. Peak was found to be $298 \mathrm{~nm}$. (fig.8).
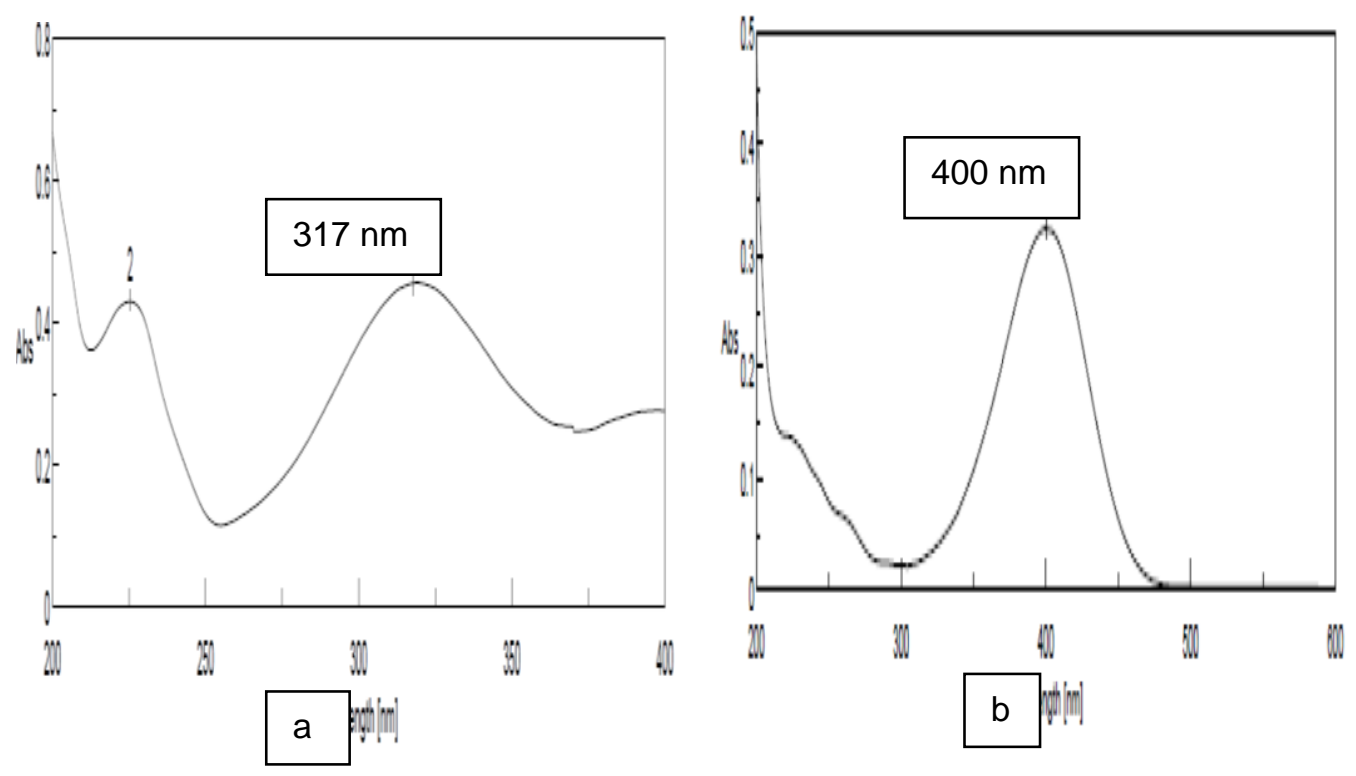


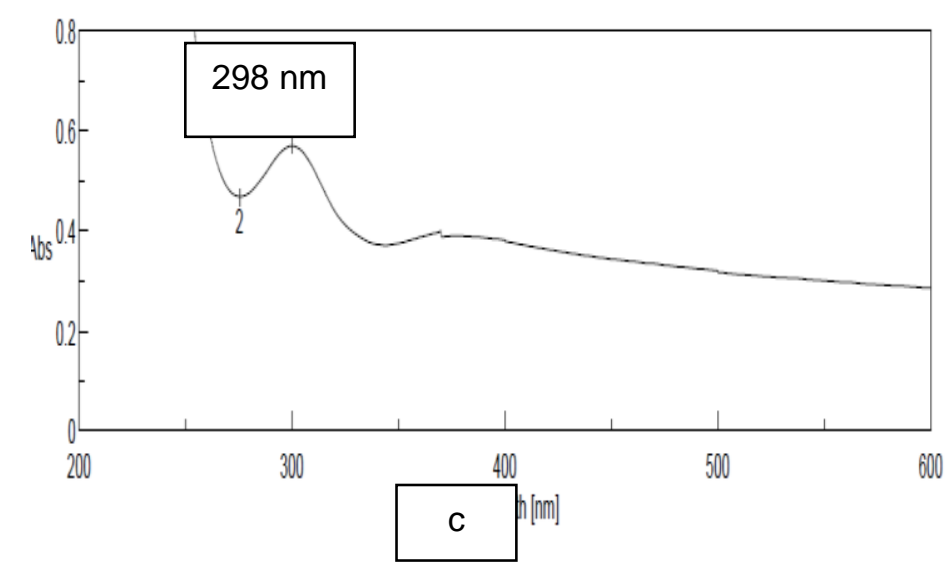

Fig. 8: UV spectra recorded during the reduction of4-NP with $\mathrm{NABH}_{4}$ catalysed by AgNPs

Thus the catalytic activity of green synthesized silver nanoparticles towards the reduction of $p$ Nitrophenol was examined through UV Vis absorption spectroscopy. A clear-cut visual changes can be noticed when $p$-Nitrophenol changes to $p$-aminophenol in presence of AgNP and $\mathrm{NaBH}_{4}$. Colour darkening is very obvious owing to formation of $p$-amino phenolate ion from $p$ nitro-phenolate as shown in fig.9.

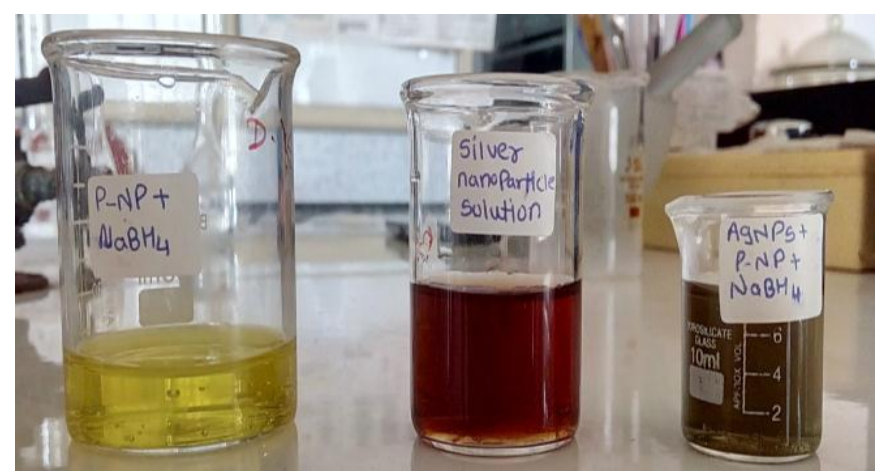

Fig. 9: Color change observed during reaction process

\section{vi. Silver nanoparticles as degradation of organic dyes}

\section{UV-vis spectroscopy of methylene blue (MB)}

The MB oxidation and reduction were carefully demonstrated from the electron reduction and oxidation abilities of $\mathrm{MB}$ at ground state without using catalyzer like $\mathrm{NaBH}_{4}$. The catalytic activity of the AgNPs was investigated by choosing the degradation of MB. The characteristic absorption peak at $662 \mathrm{~nm}$ of MB was used for monitoring the catalytic degradation process. The absorption spectra of aqueous solution of MB tested after $24 \mathrm{hrs}$. in the presence AgNPs is shown in Fig.10. The main peak at $662 \mathrm{~nm}$ decreased gradually with the extension of the exposure time, indicating the degradation of MB dye.
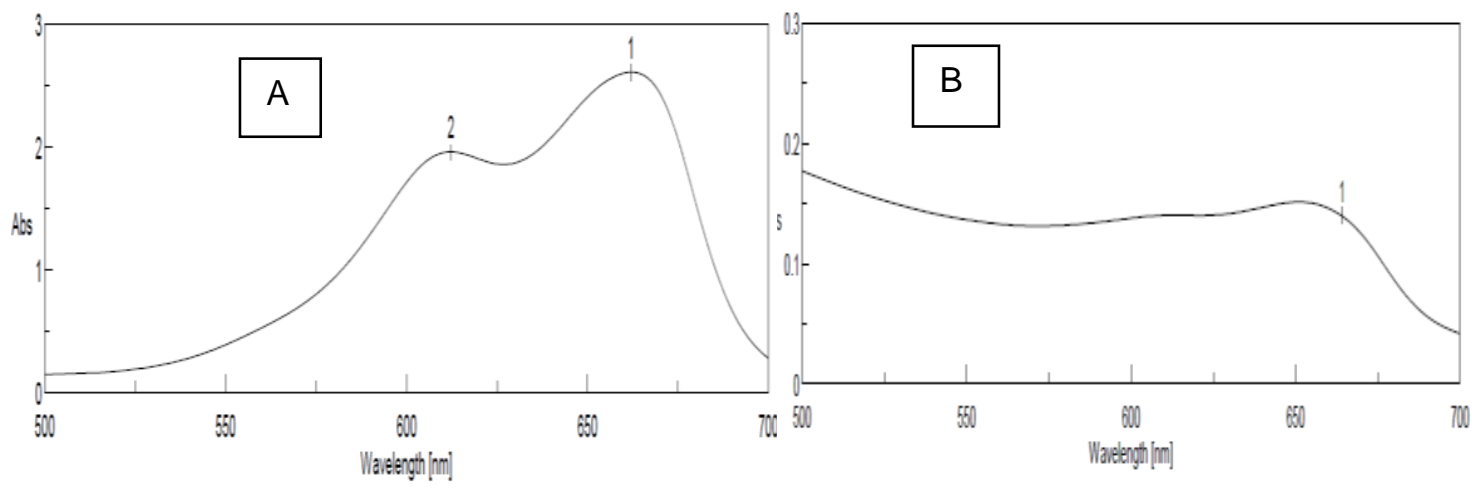

Fig. 10: UV-Vis spectra of A)only methylene blue and B) with AgNPs 


\section{UV-VIS Spectroscopy of methyl orange (MO)}

We studied the degradation of wastewater containing Methyl Orange MO, a commonly used azo dye using green synthesized AgNPs as catalysts. Fig.11 represents that the absorption band of $\mathrm{MO}$ is known to appear at $464 \mathrm{~nm}$. It can be observed that after adding AgNPs to the $\mathrm{MO}$, the absorption band of $\mathrm{MO}$ at $464 \mathrm{~nm}$ gradually decreases after $24 \mathrm{hrs}$.
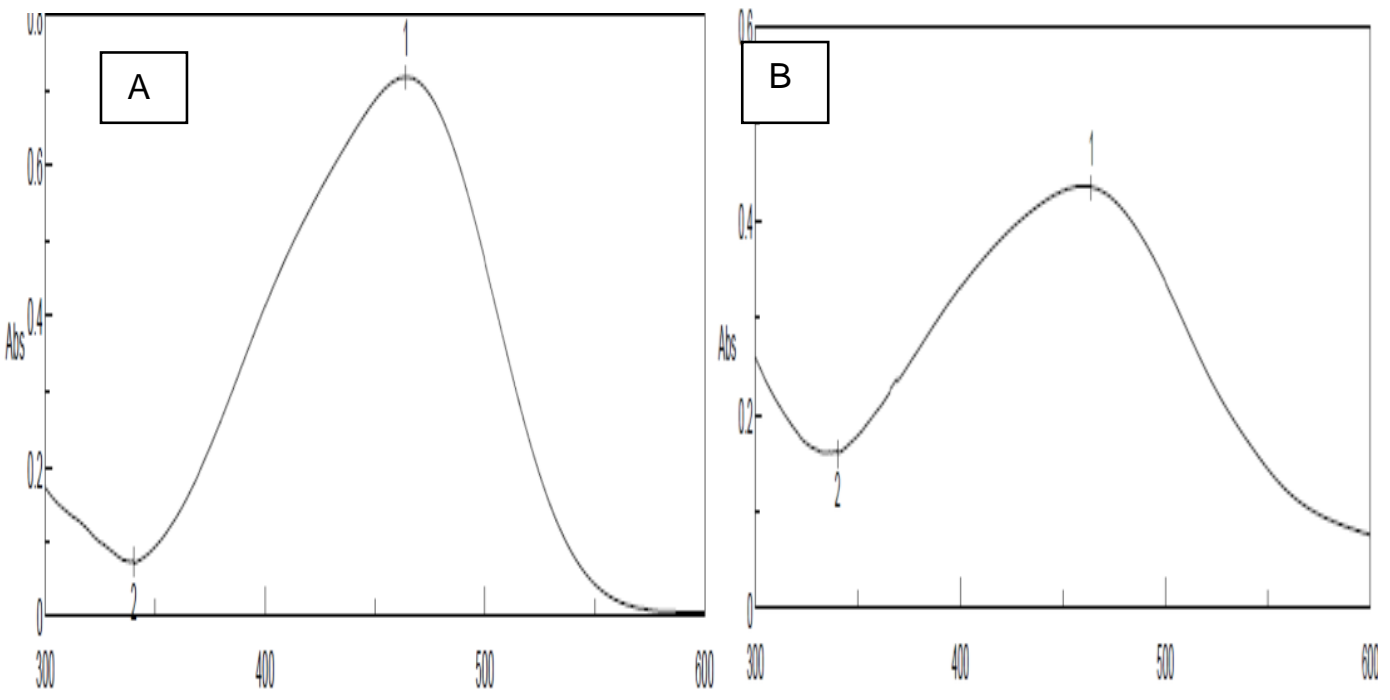

Fig. 11: UV-Vis spectra of A) only methyl orange and B) with AgNPs
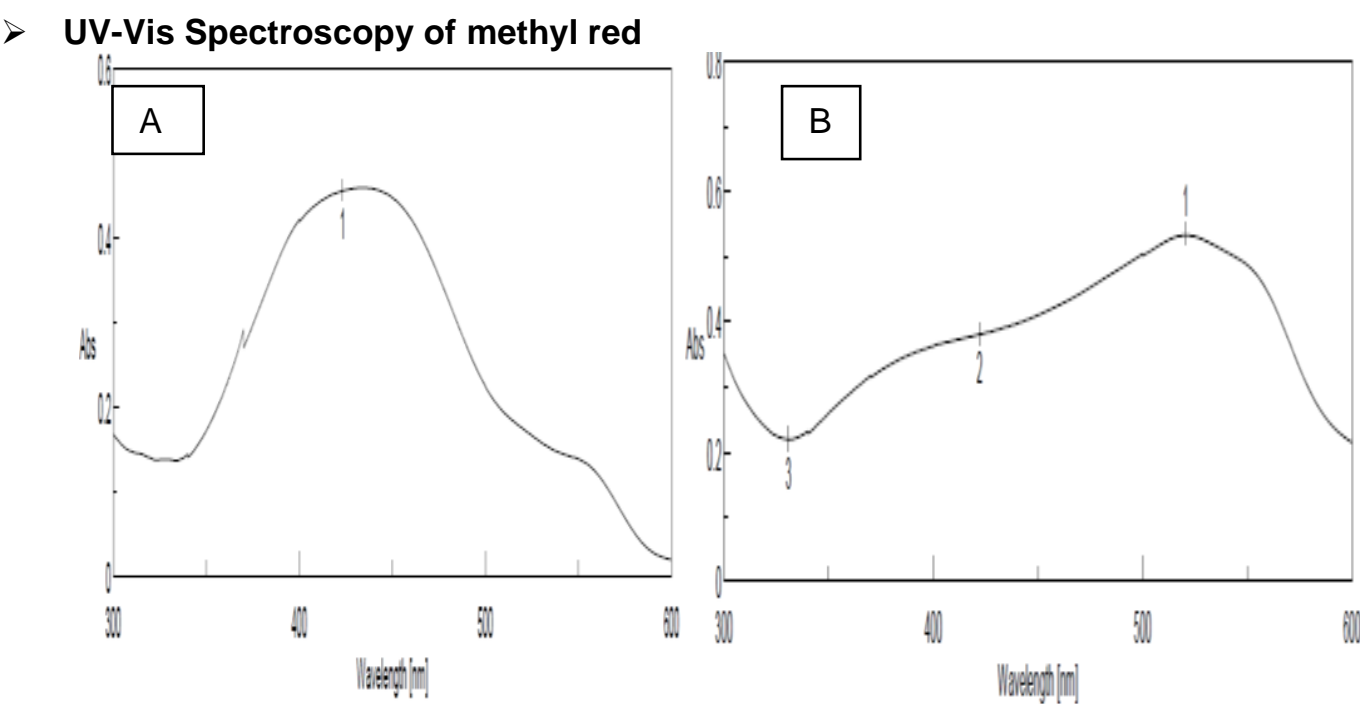

Fig. 12: UV-Vis spectra of A)only methyl red and B) with AgNPs

The release of dye effluents from textile industry is a major source of water pollution. Methyl red is one of pollutant of waste water and has potential threat to the environment; therefore, treatment of Methyl red is highly desirable. Fig 12 shows the degradation of Methyl red in the presence of AgNPs as catalysts. The main absorption peak at $423 \mathrm{~nm}$ decreased gradually after $24 \mathrm{hrs}$. indicating the catalytic degradation of Methyl red dye.

\section{CONCLUSION}

The major focuses of current research work of studies in nanoparticles by green route have been on AgNPs synthesis to obtain AgNPs with optimum surface charge, shape, size and colloidal stability. We were successful in obtaining AgNPs particle size between $30-50 \mathrm{~nm}$ by using white melon fruit extract as bioreductant. This green method is really found to be the simple, easy, cost effective and ecofriendly for the synthesis of AgNPs. Six months of stability study of the green synthesized silver nanoparticle showed no aggregation or any significant changes. 
Silver nanoparticles with best antioxidant activity at 7 and $15 \mathrm{mM}$ showed appreciable anticancer activity against two cell lines namely were Hep-G2 (Human) and MCF-7 Breast Cancer (Human) Species cell lines using Sulforhodamine B Assay.

We were also successful to study degradation of organic dyes suggested their potential use in removing oxidizable impurities from wastewater.

\section{ACKNOWLEDGEMENTS}

We thank Principal, Dr. L. H. Hiranandani College of Pharmacy for research facilities and support, IIT, Mumbai for CRAYO SEM and Anti-Cancer Drug screening facility (ACDSF) at ACTREC, Tata Memorial Centre, Navi Mumbai for in vitro SRB assay for anti-cancer activity evaluation for AgNPs.

\section{REFERENCES}

1. Kaviya S, Santhanalakshmi J and Viswanathan B. Green synthesis of silver nanoparticles using Polyalthia longifolia leaf extract along with D-sorbitol study of antibacterial activity. Journal of nanotechnology. 2011.

2. Crabtree JH, Burchette RJ, Siddiqi RA, Huen IT, Hadnott LL and Fishman A. The efficacy of silver-ion implanted catheters in reducing peritoneal dialysis-related infections. Peritoneal Dialysis International. 2003;23:368-374.

3. Bradley and Philip. Book numbering: The importance of the ISBN 25-26.(acses on oct.22) 1992.

4. Thakkar KN, Mhatre SS and Parikh R. Biological synthesis of metallic nanoparticles. Nanomedicine: Nanotechnology, Biology and Medicine. 2010;257-262.

5. Królikowska A, Kudelski A, Michota A and Bukowska J. SERS studies on the structure of thioglycolic acid monolayers on silver and gold. Surface science. 2003;227-232.

6. Zhao $G$ and Stevens SE. Multiple parameters for the comprehensive evaluation of the susceptibility of Escherichia coli to the silver ion. Biometals.1998;27-32.

7. Daniel MC and Astruc D. Gold nanoparticles: assembly, supramolecular chemistry, quantumsize-related properties, and applications toward biology, catalysis, and nanotechnology. Chemical reviews. 2004;293-346.

8. Bindhu MR and Umadevi M. Antibacterial and catalytic activities of green synthesized silver nanoparticles. Spectrochimica Acta Part A: Molecular and Biomolecular Spectroscopy. 2015;373-378.

9. Wardman P. Reduction potentials of one-electron couples involving free radicals in aqueous solution. Journal of Physical and Chemical Reference Data. 1989;1637-1755.

10. Lakshmanan G, Sathiyaseelan A, Kalaichelvan PT and Murugesan K. Plant-mediated synthesis of silver nanoparticles using fruit extract of Cleome viscosa L. Assessment of their antibacterial and anticancer activity. Karbala International Journal of Modern Science. 2018;61-68. 